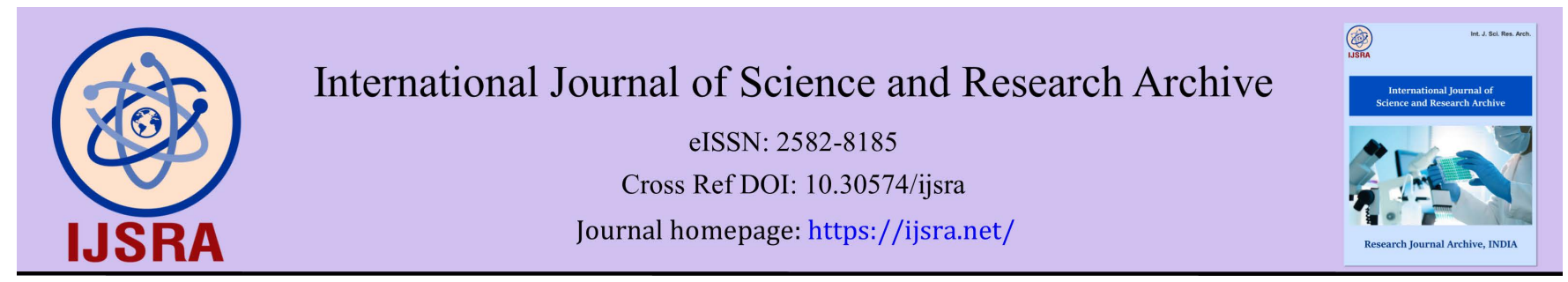

(CASE REPORT)

\title{
Treatment of idiopathic pulmonary fibrosis with an extracellular vesicle isolate product
}

Richard Bligh *

777 S New Ballas Rd, Suite 200 E, St Louis, MO 63141.

International Journal of Science and Research Archive, 2021, 02(02), 231-236

Publication history: Received on 04 April 2021; revised on 19 May 2021; accepted on 22 May 2021

Article DOI: https://doi.org/10.30574/ijsra.2021.2.2.0060

\begin{abstract}
Idiopathic Pulmonary Fibrosis (IPF) is associated with serious morbidity and mortality. Airway epithelial cell injury is important in IPF pathogenesis. Injured lung epithelial cells are a source of inflammatory mediators such as TNF- $\alpha$, IL$1 \beta$, GM-CSF, TGF $\beta$, and CXCL-8. Mesenchymal Stem Cells (MSCs) have many anti-inflammatory properties. The clinical efficacy of using mesenchymal stem cells for regenerative medicine is not dependent on the living cells but entirely on their paracrine release of growth factors (GFs) and Extracellular Vesicles (EVs). This a case report of a 74-year-old white male diagnosed with IPF. He had extreme SOB with even small amounts of exertion. CT scanning was consistent with IPF. He was treated with nebulized and IV XoFloTM, a bone marrow derived mesenchymal stem cell extracellular vesicle isolate acellular product. He experienced significant objective improvements with his IPF. His room 02 went from the high 70's to the high 90's with improved PFTs.
\end{abstract}

Keywords: Mesenchymal Stem Cells; Pulmonary Fibrosis; Extracellular vesicles; Exosomes

\section{Introduction}

Idiopathic pulmonary fibrosis (IPF) is a chronic, progressive Interstitial Lung Disease (ILD) of unknown cause in which patients experience worsening lung function resulting from progressive fibrosis. IPF is associated with high rates of morbidity and mortality [1]. Two pharmacological therapies (nintedanib and pirfenidone) have been shown to slow decline in lung function in patients with IPF [1-5]. The United States Food and Drug Administration and European Medicines Agency approvals of nintedanib, and pirfenidone changed the treatment paradigm in IPF and increased understanding of the underlying disease mechanisms [5]. Nintedanib, a tyrosine kinase inhibitor initially developed as an anti-tumor agent,[6] was noted to have activity against fibroblasts through inhibition of vascular endothelial growth factor (VEGF) and other profibrotic mediators such as Platelet-Derived Growth Factor (PDGF), Fibroblast Growth Factor (FGF), and Transforming Growth Factor (TGF)- $\beta[7,8]$. Pirfenidone is a novel compound with anti-inflammatory and anti-fibrotic properties $[9,10]$.

Progressive pulmonary fibrosis is the hallmark of IPF, but this phenotype occurs in other interstitial lung diseases [ILDs] $[11,12]$. In general, treatment for these diseases involves off-label use of corticosteroids and immunosuppressive agents [12] Due to mechanistic similarities between IPF and progressive fibrosing ILD, nintedanib therapy is under investigation in systemic sclerosis-ILD (SSc-ILD) and in other progressive fibrosing ILDs [13].

Interleukin-13 (IL-13) is a T-helper type 2 (Th2) cell cytokine that promotes lung fibrogenesis in a number of experimental settings [14-16]. Targeting of IL-13 in pre-clinical studies therapeutically blocks aberrant lung remodeling and promotes repair [16]. Three monoclonal antibody (Mab) inhibitors of IL-13 are currently in phase II clinical trial development; lebrikizumab (Hoffmann-La Roche, Basel, Switzerland, NCT01872689), tralokinumab (MedImmune LLC,

\footnotetext{
* Corresponding author: Richard Bligh, E-mail: richard@drblighmd.com

777 S New Ballas Rd, Suite 200 E, St Louis, MO 63141.

Copyright (C) 2021 Author(s) retain the copyright of this article. This article is published under the terms of the Creative Commons Attribution Liscense 4.0.
} 
Gaithersburg, MD, USA, NCT01629667), and SAR156597 (Sanofi, Paris, France, NCT02345070), the latter a bispecific monoclonal antibody against both IL-4 and IL-13. Data from these trials is awaited.

Monocytes and macrophages have a key role in regulating tissue repair and fibrosis, and several molecular pathways regulating their activity are being investigated as potential treatments in IPF $[17,18]$. Pentraxin-2 (PTX-2), also known as serum amyloid $\mathrm{P}$, is a circulating protein which binds to $\mathrm{Fc}$-gamma receptors on monocytes and promotes epithelial healing [19]. Low circulating levels of PTX-2 have been found in IPF [20]. PRM-151 (Promedior, Lexington, MA, USA, NCT02550873) is a recombinant form of PTX-2, found to be safe and well tolerated in phase I clinical trials $[21,22]$ It is presently being studied in a phase II placebo-controlled randomized clinical trial (NCT02550873).

Currently, the field of regenerative medicine is utilizing first generation stem cell technology and therapies to treat IPF $[23,24]$. Additionally, autologous treatments rely on obtaining extremely rare viable mesenchymal stem cells (MSC) from the patient's bone marrow or adipose tissue [25]. The problem inherent to any autologous cell source is cell quantity and donor variability. The safety concerns of using intravenous mesenchymal stem or stromal cells as a therapy is that these cells will become trapped in the pulmonary capillaries and cause micro-emboli and infarcts that can exacerbate the IPF. A second-generation regenerative medicine product has been developed and is currently in clinical use [26,27]. The Extracellular Vesicle Isolate Product (EVIP) is derived from bone marrow mesenchymal stem cells of a young healthy adult donor. The donor screening and testing was performed by a CLIA licensed laboratory for the presence of any virus or infective agents. The isolated bone marrow MSCs (bmMSCs) are fully characterized and have a master file recorded with the FDA. The EVIP is made using cGMP manufacturing methods to ensure the highest possible safety profile achievable and sterilization is achieved through ultrafiltration, not radiation to maintain bioactivity [28]. The bmMSC growth factors and EVs, including exosomes, are created using a proprietary process to maximize the numbers of anti-inflammatory and regenerative growth factors and RNAs. The EVs do not contain DNA or mitochondria. EVIP concentration and GF protein content is evaluated for each production lot to verify every product vial meets strict product release specifications. The EVIP product is currently being used intravenously under an FDA IND trial to treat COVID-19 associated ARDS (EXIT COVID-19) [29]. The acellular product contains over 1,000 different active GFs and cytokines and well over 30 billion extracellular vesicles per cc. The EVIP arrives frozen, to maintain bioactivity, which is then thawed to room temperature prior to use.

This is a case report of a patient with a clinical diagnosis of IPF and treated with an IV infusion of XoFlo ${ }^{\mathrm{TM}}$ EVIP. $^{\circ}$

\section{Case Study}

Patient is a 74-year-old white male diagnosed with IPF in November 2018. He was experiencing Shortness of Breath (SOB) when walking approximately 100 feet (from his home to his boat dock). He also noted extreme shortness of breath walking up a 30\% incline and 25-30 feet from his home (to his mailbox).

His initial oxygen saturation was in the high 70 s to low 80 s. A chest x-ray showed no acute cardiopulmonary changes. A high-resolution CT of the chest performed on November 28, 2018 showed mild emphysema thickening of the intralobular septa and ground glass opacities throughout both lungs consistent with a diagnosis of IPF. These findings were new compared to a CT previously performed on June 27, 2018 which showed only mild emphysema. The patient was placed on $4 \mathrm{~L} / \mathrm{min}$ of oxygen with improvement in oxygen saturations to $90 \%$. Pulmonary function tests were also performed at that time and his forced expiratory volume in one second (FEV1 was $2.23 \mathrm{~L}$. There was no improvement with the use of bronchodilators. He was placed on nintedanib (Ofev).

In February of 2019 adipose tissue was harvested and processed for infusion of adipose derived stromal vascular fraction (SVF). At approximately 2 weeks following the infusion his oxygen saturations were approximately $92 \%$ on 4L/min. He felt like he had less shortness of breath but still remained on 4L/min of oxygen. On August 7, 2019 the patient was given 2 cc of nebulized ExoFlo (Direct Biologics, Austin TX). He had repeat pulmonary function tests on November 4, 2019 with a slight improvement of his FEVl to $2.54 \mathrm{~L}$.

The patient noticed improvement after inhaled ExoFlo and returned to the office on May 20, 2020. At that time, he was given $10 \mathrm{cc}$ of ExoFlo intravenously. He returned on August 16, 2020 and was given an additional 5 cc of XoFlo intravenously. Following this last treatment, he noted significant improvement of his shortness of breath. 


\section{Results and discussion}

Patient is a 74-year-old white male diagnosed with IPF in November 2018. He had extreme SOB with even small amounts of exertion. His room 02 was in the high 70's. CT scanning was consistent with IPF.

The patient was placed on $4 \mathrm{~L} / \mathrm{min}$ of oxygen with improvement in oxygen saturations to $90 \%$. Pulmonary function tests were also done at that time and his FEV1 was $2.23 \mathrm{~L}$. There was no improvement with the use of bronchodilators. He was placed on nintedanib (Ofev).

In February of 2019 adipose tissue was harvested and processed for IV infusion of adipose Stromal Vascular Fraction (SVF). This treatment did not improve his $\mathrm{O}_{2}$ saturation. Because there was no improvement with the autogenous adipose SVF, on August 7, 2019 the patient was given 2 cc of nebulized XoFlo ${ }^{\mathrm{TM}}$. He had a repeat pulmonary function tests on November 4, 2019 with a slight improvement of his FEVl from $2.23 \mathrm{~L}$ on 11/28/18 to 2.54 on 10/4/19.

The patient noticed improvement after inhaled XoFlo and returned to the office on May 20, 1920. At that time, he was given 10 cc of XoFlo intravenously. He returned on August 16, 1920 and was given an additional 5 cc of XoFlo intravenously. Following this last treatment, he noted significant improvement of his SOB. Follow up PFTs and highresolution CT scans show no progression of his IPF. His current $\mathrm{O}_{2}$ saturation are 95 to $97 \%$ on room air. He is clinically improved with dramatically less SOB.

Idiopathic Pulmonary Fibrosis (IPF) is associated with serious morbidity and mortality. Acute exacerbations of IPF are associated with worsening symptoms, including breathlessness, decreased quality of life (QOL) and an accelerated loss of lung function $[20,21]$.

The persistence of inflammation is characteristic of IPF and it is plausible that EVs play a key role in IPF by reducing this inflammation [22,23]. IPF is induced by chronic exposure of the airway to irritants including cigarette smoke which leads to epithelial cell injury, destruction of pulmonary capillary vasculature, acceleration of epithelial cell senescence, and airway remodeling which results in the loss of lung function [20,21] Endothelial cell injury within the lung parenchyma is an important factor in emphysema and a group of endothelial-derived microparticles (EMPs) are increased in patients with stable COPD and during exacerbation. These EMPs contain vascular endothelial-cadherin, platelet endothelial cell adhesion molecule, and E-selectin. Importantly, the level of EMPs in stable IPF significantly correlated with lung destruction and airflow limitation. These results indicate the close relationship between endothelial lung injury and EMP function in the pathophysiology of IPF.

Airway epithelial cell injury is also important in IPF pathogenesis. Injured lung epithelial cells are a source of inflammatory mediators such as TNF- $\alpha, \mathrm{IL}-1 \beta, \mathrm{GM}-\mathrm{CSF}, \mathrm{TGF} \beta$, and CXCL- 8 which may act in both autocrine and paracrine manners. TGF $\beta$ induces the remodeling of airway cells by regulation and promoting of myofibroblast differentiation which is the main cause of fibrosis development during airway remodeling. The level of TGF $\beta$ in the small airway epithelium of COPD patients is correlated with the severity of airway obstruction. The paracrine activity of these mediators is controlled, at least in part, by EV signals including exosomes [22,23].

As previously stated, Inflammation is a key pathological feature of the IPF process. For example, cytokines produced by macrophages and monocytes at the site of inflammation play a key role in atherogenesis and coronary heart disease. Proinflammatory biomarkers, such as cytokines, have been found in both chronic and acute pulmonary disease states, suggesting either a direct or facilitator role in the occurrence of the pathology. Multiple cytokines are produced during an inflammatory reaction. Cytokines contribute to inflammatory processes by activation of specific signal transduction mechanisms as well as the activation of other cell types. Cytokines are found extracellularly (in blood) and in interstitial compartments, where they can activate cells in an autocrine/paracrine fashion. It has been postulated that increased levels of cytokines influence and contribute to IPF by increasing the sensitization of nociceptors. When tissue is invaded or destroyed by pulmonary leukocytes during an inflammatory episode, several mediators such as interleukin-1 (IL-1), IL-6, IL-8 and tumor necrosis factor alpha (TNF- $\alpha$ ) migrate to the site. Also included in these mediators are nerve growth factor and prostaglandins. All of these are causes of pulmonary inflammation [20-23].

Mesenchymal stem cells (MSCs) have many anti-inflammatory properties. In many types of pulmonary trauma, inflammatory conditions at the site of injury impede the natural repair processes by local progenitor and mature cells. MSCs assist via paracrine mechanisms and modulate the regenerative environment via anti-inflammatory and immunomodulatory mechanisms. In response to inflammatory molecules such as interleukin-1 (IL-1), IL-2, IL-12, tumor necrosis factor- $\alpha$ (TNF- $\alpha$ ) and interferon-gamma (INF- $\gamma$ ), MSCs secrete an array of growth factors and antiinflammatory proteins with complex feedback mechanisms among the many types of immune cells. The key 
immunomodulatory cytokines include prostaglandin E2 (PGE2), TGF- $\beta 1$, HGF, SDF-1, indoleamine 2, 3-dioxygenase, IL4, IL-10, IL-1 receptor antagonist and soluble tumor necrosis factor-a receptor. MSCs prevent proliferation and function of many inflammatory immune cells, including T cells, natural killer cells, B cells, monocytes, macrophages and dendritic cells [24].

A characteristic of chronically inflamed environments is a persistent imbalance in the types of helper $\mathrm{T}$ cells and macrophages. MSCs indirectly promote the transition of $\mathrm{TH}_{1}$ to $\mathrm{TH}_{2}$ cells by reducing INF- $\gamma$ and increasing IL- 4 and IL10. The restored $\mathrm{TH}_{1} / \mathrm{TH}_{2}$ balance has been shown to improve tissue regeneration in cartilage, muscle and other soft tissue injuries, alleviate symptoms of autoimmune diseases and have an anti-diabetic effect. Similarly, reduction in INF$\gamma$ and secretion of IL-4 promotes a shift in macrophages from M1 (pro-inflammatory, anti-angiogenic and tissue growth inhibition) to M2 (anti-inflammatory, pro-remodeling and tissue healing) type, an effect required for skeletal, muscular and neural healing and regeneration [24].

Undifferentiated MSCs express low to medium levels of human leukocyte antigen (HLA) Class I and low levels of HLA Class II to avoid recognition by the immune system. This property gives donor MSCs a so-called 'stealth' ability to go undetected by a host immune system in allogeneic therapies. However, Class I antigen is present at detectable levels and Class II antigen expression can be induced by INF-y. Several cases of allogeneic MSC rejection and chronic immune responses have been reported in animal studies and human clinical trials. This entire problem would be avoided using only the mesenchymal stem cell Secretome, which includes proteins, peptides, glycosaminoglycans, proteoglycans, chemokines, cytokines and extracellular vesicles including exosomes collected from the conditioned growth media [24].

Currently, regenerative medicine is utilizing first generation technology. All current autogenous treatments rely on obtaining extremely small numbers of a viable mesenchymal stem cells from the patient's own bone marrow or adipose tissue. The other allogeneic sources for the mesenchymal stem cell are perinatal, such as placenta, amniotic fluid or umbilical cord blood. All current therapies that rely on the delivery of living cells will be made obsolete by the extracellular vesicle isolate product (EVIP) [24].

It has become increasingly understood by researchers and clinicians that the clinical efficacy of using mesenchymal stem cells for regenerative medicine is not dependent on the living cells but entirely on their paracrine release of growth factors (GFs) and EVs. The cells are not required. The future of regenerative medicine is the use of acellular signaling products. EVIP acellular signals derived from bone marrow MSCs provide a consistent product that has extensive characterization, which includes advanced particle analysis, proteomic evaluation and USP $<71>$ sterility assurance. Thorough cytokine and growth factor identification and quantification has been performed on the EVIP. Think of EVIP acellular exosomes as a bio-pharmacological quality product that is consistent, standardized and quality tested regarding dose and biological activity [24].

\section{Conclusions of Pulmonary Function Tests from 10/4/2019}

- Spirometry shows normal with no response to bronchodilators (this does not preclude the use of bronchodilators).

- Improvement to bronchodilators in the small airways.

- Diffusion capacity is found to be moderately reduced and is not corrected for hemoglobin.

- Lung volumes show normal.

- Airway resistance shows increased.

- Flow volume loop shows expiratory loop obstruction with normal inspiratory loop.

- Volume time curve shows good patient effort.

- ABGs were not performed.

- Improvement in FEVl on November 4, 2019 from 2.23 L to 2.54 L

\section{Compliance with ethical standards}

\section{Statement of informed consent}

Informed consent was obtained from all individual participants included in the study.

\section{References}

[1] Lederer DJ, Martinez FJ. Idiopathic pulmonary fibrosis. N Engl J Med. 2018; 378: 1811-23. 
[2] Richeldi L, du Bois RM, Raghu G, Azuma A, Brown KK, Costabel U, Cottin V, Flaherty KR, Hansell DM, Inoue Y, Kim DS, Kolb M, Nicholson AG, Noble PW, Selman M, Taniguchi H, Brun M, Le Maulf F, Girard M, Stowasser S, Schlenker-Herceg R, Disse B, Collard HR. Efficacy and safety of nintedanib in idiopathic pulmonary fibrosis. N Engl J Med. 2014; 370: 2071-82.

[3] Richeldi L, du Bois RM, Raghu G, Azuma A, Brown KK, Costabel U, Cottin V, Flaherty KR, Hansell DM, Inoue Y, Kim DS, Kolb M, Nicholson AG, Noble PW, Selman M, Taniguchi H, Brun M, Le Maulf F, Girard M, Stowasser S, Schlenker-Herceg R, Disse B, Collard HR. Efficacy and safety of nintedanib in idiopathic pulmonary fibrosis. N Engl J Med. 2014; 370: 2071-82.

[4] King TE, Bradford WZ, Castro-Bernardini S, Fagan EA, Glaspole I, Glassberg MK, Gorina E, Hopkins PM, Kardatzke D, Lancaster L, Lederer DJ, Nathan SD, Pereira CA, Sahn SA, Sussman R, Swigris JJ, Noble PW. A phase 3 trial of pirfenidone in patients with idiopathic pulmonary fibrosis. N Engl J Med. 2014; 370: 2083-92.

[5] Rivera-Ortega P, Hayton C, Blaikley J, Leonard C, Chaudhuri N. Nintedanib in the management of idiopathic pulmonary fibrosis: clinical trial evidence and real-world experience. Ther Adv Respir Dis. 2018; 12: 1753466618800618.

[6] Hilberg F, Roth GJ, Krssak M, Kautschitsch S, Sommergruber W, Tontsch-Grunt U, Garin-Chesa P, Bader G, Zoephel A, Quant J, et al. BIBF 1120: Triple angiokinase inhibitor with sustained receptor blockade and good antitumor efficacy. Cancer Res. 2008; 68: 4774-4782.

[7] Wollin L, Maillet I, Quesniaux V, Holweg A, Ryffel B. Antifibrotic and anti-inflammatory activity of the tyrosine kinase inhibitor nintedanib in experimental models of lung fibrosis. J. Pharmacol. Exp. Ther. 2014; 349: 209-220.

[8] Wollin L, Wex E, Pautsch A, Schnapp G, Hostettler KE, Stowasser S, Kolb M. Mode of action of nintedanib in the treatment of idiopathic pulmonary fibrosis. Eur. Respir. J. 2015; 45: 1434-1445.

[9] Kaneko M, Inoue H, Nakazawa R, Azuma N, Suzuki M, Yamauchi S, Margolin SB, Tsubota K, Saito I. Pirfenidone induces intercellular adhesion molecule-1 (ICAM-1) down-regulation on cultured human synovial fibroblasts. Clin. Exp. Immunol. 1998; 113: 72-76.

[10] Oku H, Shimizu T, Kawabata T, Nagira M, Hikita I, Ueyama A, Matsushima S, Torii M, Arimura A. Antifibrotic action of pirfenidone and prednisolone: Different effects on pulmonary cytokines and growth factors in bleomycininduced murine pulmonary fibrosis. Eur. J. Pharmacol. 2008; 590: 400-408.

[11] Flaherty KR, Brown KK, Wells AU, Clerisme-Beaty E, Collard HR, Cottin V, Devaraj A, Inoue Y, Le Maulf F, Richeldi L, Schmidt H, Walsh S, Mezzanotte W, Schlenker-Herceg R. Design of the PF-ILD trial: a double-blind, randomised, placebo-controlled phase III trial of nintedanib in patients with progressive fibrosing interstitial lung disease. BMJ Open Respir Res. 2017; 4: e000212.

[12] Richeldi L, Varone F, Bergna M, de Andrade J, Falk J, Hallowell R, Jouneau S, Kondoh Y, Morrow L, Randerath W, Strek M, Tabaj G. Pharmacological management of progressive-fibrosing interstitial lung diseases: a review of the current evidence. Eur Respir Rev. 2018; 27: 180074.

[13] Flaherty KR, Brown KK, Wells AU, Clerisme-Beaty E, Collard HR, Cottin V, Devaraj A, Inoue Y, Le Maulf F, Richeldi L, Schmidt H, Walsh S, Mezzanotte W, Schlenker-Herceg R. Design of the PF-ILD trial: a double-blind, randomised, placebo-controlled phase III trial of nintedanib in patients with progressive fibrosing interstitial lung disease. BMJ Open Respir Res. 2017; 4: e000212.

[14] Zhu Z, Homer RJ, Wang Z, Chen Q, Geba GP, Wang J, Zhang Y, Elias JA. Pulmonary expression of interleukin-13 causes inflammation, mucus hypersecretion, subepithelial fibrosis, physiologic abnormalities, and eotaxin production. J. Clin. Investig. 1999; 103: 779-788.

[15] Belperio JA, Dy M, Burdick MD, Xue YY, Li K, Elias JA, Keane MP. Interaction of IL-13 and C10 in the pathogenesis of bleomycin-induced pulmonary fibrosis. Am. J. Respir. Cell. Mol. Biol. 2002; 27: 419-427.

[16] Murray LA, Zhang H, Oak SR, Coelho AL, Herath A, Flaherty KR, Lee J, Bell M, Knight DA, Martinez FJ, et al. Targeting interleukin-13 with tralokinumab attenuates lung fibrosis and epithelial damage in a humanized SCID idiopathic pulmonary fibrosis model. Am. J. Respir. Cell. Mol. Biol. 2014; 50: 985-994.

[17] Barratt SL, Creamer A, Hayton C, Chaudhun N, Idiopathic Pulmonary Fibrosis (IPF): An overview. J Clin Med. Aug 2018; 7(8): 201.

[18] Valenzuela C, Torrisi SE, Kakn N, Ongoing Challenges in Pulmonary Fibrosis and Insights from the Nintedanib Clinical Programme. Respiratory Research, 2020; 21: 7. 
[19] Cox N, Pilling D, Gomer RH. Serum amyloid P: a systemic regulator of the innate immune response. J. Leukocyte Bio. 2014; 96: 739-743.

[20] Castaño AP, Lin SL, Surowy T, Nowlin BT, Turlapati SA, Patel T, Singh A, Li S, Lupher ML, Duffield JS. Serum amyloid P inhibits fibrosis through Fc gamma R-dependent monocyte-macrophage regulation in vivo. Sci. Transl. Med. 2009; 1.

[21] Dillingh MR, van den Blink B, Moerland M, van Dongen MG, Levi M, Kleinjan A, Wijsenbeek MS, Lupher ML, Harper DM, Getsy JA, et al. Recombinant human serum amyloid P in healthy volunteers and patients with pulmonary fibrosis. Pulm. Pharmacol. Ther. 2013; 26: 672-676.

[22] van den Blink B, Dillingh MR, Ginns LC, Morrison LD, Moerland M, Wijsenbeek M, Trehu EG, Bartholmai BJ, Burggraaf J. Recombinant human pentraxin-2 therapy in patients with idiopathic pulmonary fibrosis: Safety, pharmacokinetics and exploratory efficacy. Eur. Respir. J. 2016; 47: 889-897.

[23] Glassberg MK, Minkiewicz J, Toonkel RL, Simonet ES, Rubio GA, DiFede D, Shafazand S, Khan A, Pujol MV, LaRussa VF, Lancaster LH, Rosen GD, Fishman J, Mageto YN, Medizabal A, Hare JM. Allogeneic Human Mesenchymal Stem Cells in Patients With Idiopathic Pulmonary Fibrosis via Intravenous Delivery (AETHER): A Phase I Safety Clinical Trial. Chest. 2017; 151(5): 971-981.

[24] Li X, Yue S, Luo Z. Mesenchymal stem cells in idiopathic pulmonary fibrosis. Oncotarget. 2017; 8(60): 102600102616.

[25] Zhu Y, Feng X, et. Al., Human Mesenchymal Stem Cell Microvesicles for the Treatment of E. coli Endotoxin-induced acute lung injury in mice. Stem Cells. Jan 2014; 32(1): 116-125.

[26] Alipoor SD, Mortaz E, et al, Exosomes and exosomal miRNA in Respiratory Diseases. Mediators Inflamm. 25 Sept 2016.

[27] Phinney DG, Pittenger MF, Concise Review: MSC-Derived Exosomes for Cell-Free Therapy. Stem Cells. 7 Mar 2017.

[28] Quality Assurance | Direct Biologics, LLC, accessed. 27 April 2021.

[29] Sengupta V, Sengupta S, Lazo A, Woods P, Nolan A, Bremer N. Exosomes Derived from Bone Marrow Mesenchymal Stem Cells as Treatment for Severe COVID-19. Stem Cells \& Dev. 2020; 29(12): 747-754. 